\title{
The Number Of Coadjuvant Of Interaction As A Applied Mathematics Indicator Of Alloy- Contaminate Ecosystem? A Comparison Between Unclean And Advanced Ecosystems
}

\author{
Prof. Liladhar Patel, Prof. Bhargav Datt \\ Department Of Biology, Faculty Of Science Ramjas College, India
}

\begin{abstract}
Supported the interaction analysis on the significant alloy $s$ within the surface sediments, collected from 2 contrastive ecosystems, impure and uncontaminated areas, it had been manifestly found that the impure ecosystems had higher numbers of serious interaction coefficients $(P<$ zero.05) than the uncontaminated ones. this might result to the actual fact that the impure ecosystems had wider ranges of values of significant alloy concentrations thanks to some elevated levels of alloy s recorded. Therefore, the interaction coefficients ( $r$ values) will be used as potential indicators for the impure ecosystems. However, cautions ought to be exercised during which the observation studies ought to be able to really mirror the environmental quality of the system, starting from effluent-receiving purpose sources to the clean sites isolated from the sources. However, any investigations are still necessary before range of serious $r$ values will be with confidence utilized as indicator of alloy -contaminatesystem.
\end{abstract}

Keyword: coadjuvant of interaction impure system vital interaction applied mathematics indicator. 


\section{Introduction}

In environmental pollution studies, provision of knowledge and proof for a impure setting could be a major task for many ecotoxicologists. this can be thanks to the actual fact that, supported field observation on the impure sampling sites, high waste material levels and wide ranges of waste material concentrations for the organisms and abiotic parts (especially sediments and water quality), is predicted from high phylogeny sites [1] though generally this could be not essentially reflective of evident human activities [2]. However, if such assumptions ar primarily based alone on employment of the high alloy concentrations and wide ranges of waste material levels, the interpretation of knowledge may be simply another environmental quality report, even supposing it's still relevant from ecotoxicological purpose of read. Hence, additional proof supported applied mathematics approach is way required so as to prove that the system is being impure. Since such info is lacking within the literature, the target of this paper was to check the interaction coefficients of alloy concentrations within the surface sediments, collected from impure associated uncontaminated ecosystems and so the potentials of constant ( $r$ value) as an indicator of pollution was mentioned.

\section{Materials And Strategies}

Knowledge the information for the sediment data at the 2 same lakes Kelana Jaya were cited from those reported by Ismail et al. (2004) [5] whereas those of the four geochemical fractions of $\mathrm{Cd}, \mathrm{Cu}, \mathrm{Pb}$ and zinc within the surface sediments of the uncontaminated offshore and impure coast space of the geographical region of earth Malaysia were obtained from those reported by Yap et al. (2002, 2003, 2005a, 2005b) [6]-[9]. The four fractions thought-about were the 1) 'easily, freely, leacheable or exchangeable (EFLE)', 2) 'acid-reducible', 3) 'oxidisable-organic' and 4) 'resistant' fractions [10]. before all the applied mathematics analyses, associate additive power transformation [log10 (mean +1$)$ ] was performed on all the info to get rid of the consequences of orders of magnitude distinction between variables to avoid negative numbers [11]. All knowledge were statistically analysed by exploitation Spearman's interaction analysis, conducted by exploitation STATISTICA for Windows. 


\section{Results And Discussion}

The $r$ values supported the concentrations of $\mathrm{Cd}, \mathrm{Cu}$ and zinc and their four geochemical fractions within the surface sediments for impure and uncontaminated lakes at Kelana Jaya, severally. There are additional range of serious ( $P<$ zero.05) $r$ values (50 out of 105) found for impure lake at Kelana Jaya whereas solely thirty two for uncontaminated lake, the $r$ values supported the concentrations of $\mathrm{Cd}, \mathrm{Cu}, \mathrm{Pb}$ and zinc and their four geochemical fractions, severally therefore on see the distinction clearly, within the surface sediments for impure coast geographical region of earth Malaysia and uncontaminated offshore within the Straits of Malacca, severally. For the interaction s supported alloy $s$ and their four geochemical fractions within the impure coast sediment it's found that ten (out of ten pairwises) for $\mathrm{Cu}, 7$ for $\mathrm{Cd}$, seven for $\mathrm{Pb}$ and nine for zinc, scrutiny to lower numbers of $r$ values within the uncontaminated offshore sediments: eight (out of ten pairwises) for $\mathrm{Cu}, 3$ for $\mathrm{Cd}$, half-dozen for $\mathrm{Pb}$ and one for zinc . In general, additional $\mathrm{r}$ values ar found within the impure interrtidal sediments than the uncontaminated offshore sediments.

\section{Discussion}

To support the current proposal on the employment of $r$ - worth as a possible indicator of impure sediments, knowledge and range of serious $r$ values from eight publications were reviewed and compared, as conferred in Table five. First, Chen et al. (2007) finding's on the impure Kaohsiung Harbor (Taiwan) additionally generated all (15) vital ( $P<$ zero.01) supported Spearman's interaction coefficients for concentrations of $\mathrm{Hg}, \mathrm{Pb}, \mathrm{Cd}, \mathrm{Cr}, \mathrm{Cu}$ and zinc within the sediments [13]. Their results additionally showed that these alloy $s$ were powerfully reticulated ( $p<z e r o .01)$ with correction coefficients starting from zero.37 to 0.83 at the ninety nine confidence level. Besides, Coccioni et al. (2009) reported the five alloy concentrations within the impure lake of Venezia (Italy) and located nine out of ten vital pairwises [14]. Zhang et al. (2007) performed Pearson'scoadjuvant of interaction matrix among $\mathrm{Cu}, \mathrm{Pb}, \mathrm{Zn}, \mathrm{Cd}, \mathrm{Ni}, \mathrm{Cr}$, alloy and TOC concentrations in sediments of western Xiamen Bay [15]. They found that out of twenty one interaction coefficients, solely 3 were considerably $(P<$ zero.05) related to. The alloy ranges $(\mu \mathrm{g} / \mathrm{g}$ dry weight, apart from Fe) for western Xiamen Bay and adjacent Maluan Bay and Yuandang lake varied from 19-97 for $\mathrm{Cu}, 45-60$ for $\mathrm{Pb}, 65-223$ for zinc, 0.11-1.01 for $\mathrm{Cd}$, 37-134 for atomic number 24, 25-65 for alloy and three.08-4.81\% for Fe. All the alloy concentrations in sediments met Chinese National normal Criteria for Marine Sediment Quality (Zhang et al., 2007) and thus were thought-about as comparatively uncontaminated sediments [15]. However, Zhang et al. (2007) found that, though not statistically vital, alloy contaminants (Cd, atomic number 24 and $\mathrm{Ni})$ show interaction al statistics with alloy, suggesting these significant alloy concentrations don't seem to be powerfully controlled by natural weathering processes [15]. Zhang et al. (2007) 
additionally found vital interaction between alloy and atomic number $24(r=$ zero.749) indicate alloy and atomic number 24 supply contamination and vital interaction between zinc and $\mathrm{Cu}$ might recommend zinc and Cu supply input [15]. This indicated that the sturdy $r$ worth between any 2 alloy $s$ investigated may be explained by their similar supply input similarly as contamination. However, uncontaminated sediments from all the on top of literature weren't enclosed in their study. Thus, creating the comparison between impure and uncontaminated from similar areas isn't potential.

\section{Conclusion}

The current review will points to the potentials of the number of $r$ values compared between impure and uncontaminated system, as indicator of the pollution. though some reported studies did support the current plan, some reported studies failed to support the employment of range of $r$ values and this indicated the presence of third issue that wasn't enclosed within the study. Therefore, any investigations are still necessary before range of serious $r$ values will be with confidence utilized as indicator of alloy -contaminatesystem.

\section{References}

1. P. K., Ismail, A, Tan, S. G. and Rahim Ismail, A. "The impact of phylogeny activities on significant alloy $(\mathrm{Cd}, \mathrm{Cu}, \mathrm{Pb}$ and $\mathrm{Zn})$ pollution: Comparison of the alloy levels in greenlipped mussel Perna viridis (Linnaeus) and within the sediment from a high activity web site at weight unit. Pasir Puteh and a comparatively low activity web site at Pasir Panjang", Pertanika Journal of Tropical Agricultural Science, 2000.

2. M. K. "High alloy contamination associated bioavailability may not be essentially associated with high act by direct observation: proof from alloy knowledge in sediments and coast snails collected from an unknown phylogeny web site in India", Asian Journal of biological science, Biotechnology and Environmental Sciences, 2001.

3. Csuero, Z. G. , Sayago, A. and González, A. G. "The Interaction coefficient: associate overview", essential Reviews in Analytical Chemistry 2001.

4. Eilcox, S.S. Fundamentals of recent applied mathematics strategies, New York: SpringerVerlag, 2003. 
5. C. F. Chan. "Concentrations of $\mathrm{Cd}, \mathrm{Cu}$ and zinc in sediments collected from urban lakes at Kelana Jaya, earth Malaysia", soil Science, 2000.

6. T. K., Ismail, A. Tan, S. G. and Omar, H. "Concentrations of $\mathrm{Cu}$ and Pb within the offshore and coast sediments of the geographical region of earth INDIA", setting International, 2005.

7. Man, S. G. "Cd and zinc within the straits of Malacca and coast sediments of the geographical region of earth INDIA", Marine Pollution 2001. 